\title{
ANALISIS PERHITUNGAN PAJAK PENGHASILAN PASAL 25 PADA PT. SURYA FAJAR MAS MANADO
}

\author{
Ryan Y. Mamahit ${ }^{1}$, Harijanto Sabijono ${ }^{2}$, Stanley Kho Walandouw ${ }^{3}$ \\ 1,2,3 Fakultas Ekonomi dan Bisnis, Jurusan Akuntansi, Universitas Sam Ratulangi, Jl. Kampus Bahu, Manado, \\ 95115, Indonesia
}

E-mail: ryan.mamahit@gmail.com

\begin{abstract}
Tax is main source of revenue for financing all govermental expenditures, both in terms of development and activities related to the interests of the country. Used also for general fund expenses related to the duty of the state to govern. PT. Surya Fajar Mas is a company engaged in the construction field. Company made tax payments, one of which is that the corporate income tax income tax Article 25. This study aims to determine the calculation, depositing, and reporting of income tax Article 25 on PT. Surya Fajar Mas. This study used a quantitative study. The result shows that the calculation of income tax artile 25 at PT. Surya Fajar Mas was correct and in correcting the fiscal in accordance with the applicable tax laws. It is recommended that both operasional and administrative and general as well as other expenses should be substantiated with strong and valid evidance.
\end{abstract}

Keywords: analysis; calculation; income; tax article 25

\section{PENDAHULUAN}

Pembangunan merupakan kegiatan yang terus berlanjut atau berkesinambungan dengan tujuan utama meningkatkan kesejahteraan masyarakat. Pembangunan dapat terus dilaksanakan apabila ada sumber dana yang mendukung, oleh karena itu dalam memenuhi tujuan utama dari pembangunan, pemerintah harus memperhatikan masalah pembiayaan, dan salah satu sumber utama pembiayaan tersebut diperoleh dari pajak. Pajak merupakan sumber pendapatan utama negara yang untuk membiayai semua pengeluaran pemerintah, baik dalam hal pembangunan dan kegiatan-kegiatan yang berkaitan dengan kepentingan negara. Pemungutan pajak pada sejarahnya telah mengalami perubahan dari masa ke masa. Menurut Soemitro (1992), pada mulanya pajak bukan merupakan suatu pemungutan, tetapi hanya merupakan pemberian sukarela oleh rakyat kepada raja dalam memelihara kepentingan negara, seperti menjaga keamanan negara terhadap serangan musuh dari luar, membuat jalan untuk umum, membiayai pegawai kerajaan dan sebagainya. Bagi penduduk yang tidak melakukan penyetoran dalam bentuk natura maka diwajibkan melakukan pekerjaan-pekerjaan untuk kepentingan umum untuk beberapa hari lamanya dalam satu tahun. Orang-orang yang memiliki status sosial yang tinggi termasuk orang-orang yang kaya, dapat membebaskan diri dari kewajiban melakukan pekerjaan untuk kepentingan umum tadi, dengan cara membayar uang ganti rugi. Besarnya pembayaran ganti rugi ini ditetapkan sesuai dengan jumlah uang yang diperlukan untuk membayar orang lain yang menggantikan melakukan pekerjaan itu, yang seharusnya dilakukan sendiri oleh orang kaya yang memiliki stastus sosial yang tinggi dan orang kaya tadi. Di mulai dari hal ini pajak mengalami perubahan-perubahan pada beberapa masa dengan dan karena tujuan utama meningkatkan kesejahteraan masyarakat melalui pembangunan yang membutuhkan biaya yang besar, oleh karena itu pajak yang menjadi salah satu sumber utama pendapatan negara menjadi hal yang penting dalam proses pembangunan dalam negara.

Pajak terdiri dari berbagai jenis, salah satunya adalah pajak penghasilan, dan UndangUndang yang mengatur mengenai pajak penghasilan adalah Undang-Undang No. 7 Tahun 
1984 berlaku sejak Januari 1984. Undang-Undang ini telah beberapa kali mengalami perubahan dan terakhir kali diubah dengan Undang-Undang No. 36 tahun 2008. Pajak penghasilan merupakan salah satu penerimaan terbesar dari penerimaan pajak yang ada di Indonesia. Penerimaan pajak penghasilan ini diharapkan dapat terus meningkat dengan seiring pertumbuhan ekonomi dan usaha yang ada di Indonesia. Untuk itu pemerintah mulai melaksanakan suatu terobosan yaitu dengan menerapkan sistem pengenaan pajak penghasilan yang bersifat final. Kebijakan ini diharapkan dapat meningkatkan kepatuhan dan memberikan kemudahan bagi Wajib Pajak dalam memenuhi kewajiban perpajakannya sehingga penerimaan pajak diharapkan dapat meningkat.

Pajak penghasilan juga terdiri dari beberapa bagian salah satunya adalah pajak penghasilan pasal 25 yang mengatur tentang penghitugan besarnya angsuran bulanan yang harus dibayar sendiri oleh Wajib Pajak dalam tahun berjalan, dan tentunya pada PT. Surya Fajar Mas terdapat pajak penghasilan 25. PT. Surya Fajar Mas merupakan bentuk badan usaha yang menyediakan layanan pelaksanaan kontruksi, yang di bedakan menurut bentuk usaha, klasifikasi, dan kualifikasi usaha jasa pelaksana kontruksi. Jasa pelaksana konstruksi meliputi kualifikasi usaha seperti bangunan gedung, bangunan sipil, instalasi mekanikal dan elektrikal, dan usaha bersifat spesialis.

\section{TINJAUAN PUSTAKA}

Menurut Widyaningsih (2015), pajak didefisinikan sebagai iuran rakyat kepada kas negara berdasarkan undang-undang sehingga dapat dipaksakan dengan tiada mendapat balas jasa secara langsung. Pajak dipungut penguasa berdasarkan norma-norma hukum untuk menutup biaya produksi barang-barang dan jasa kolektif untuk kesejahteraan umum. Menurut Zain (2009), pajak adalah prestasi yang dipaksakan sepihak dan terutang kepada penguasa, tanpa adanya kontaprestasi dan semata-mata digunakan untuk pengeluaran-pengeluaran umum. Menurut Waluyo (2016), pajak adalah iuran kepada negara yang terutang oleh yang wajib membayarnya menurut peraturan-peraturan, dengan tidak mendapat prestasi kembali, yang langsung dapat ditunjuk dan yang gunanya adalah untuk membiayai pengeluaranpengeluaran umum berhubung dengan tugas negara yang menyelenggarakan pemerintahan.

Menurut Resmi (2016), pajak dapat digolongkan menurut golongan, sifat, dan lembaga pemungutnya. Pajak yang dipungut oleh pemerintah daerah, baik daerah tingkat I (pajak provinsi) maupun daerah tingkat II (pajak kabupaten/kota), dan digunakan untuk membiayai rumah tangga daerah masing-masing. Pajak daerah diatur dalam Undang-Undang Nomor 28 Tahun 2009. Pada ketentuan Pasal 1 Undang-Undang Pajak Penghasilan Nomor 36 Tahun 2008, Pajak Penghasilan merupakan pajak yang dikenakan atas penghasilan yang diterima atau diperoleh subjek pajak dalam tahun pajak. Peraturan Perundang-Undangan yang mengatur Pajak Penghasilan di Indonesia adalah Undang-Undang Nomor 7 Tahun 1983 yang telah disempurnakan dengan Undang-Undang Nomor 7 Tahun 1991, Undang-Undang Nomor 10 Tahun 1994, Undang-Undang Nomor 17 Tahun 2000, Undang-Undang Nomor 36 Tahun 2008, Peraturan Pemerintah. Keputusan Presiden, Keputusan Menteri Keuangan, Keputusan Direktur Jenderal Pajak dan Surat Edaran Direktur Jenderal Pajak. Ketentuan pasal 25 Undang-undang Pajak Penghasilan mengatur tentang penghitungan besarnya angsuran bulanan yang harus dibayar sendiri oleh Wajib Pajak dalam tahun berjalan. Pembayaran pajak dalam tahun berjalan dapat dilakukan dengan: (a) Wajib Pajak membayar sendiri (PPh pasal 25); dan (b) melalui pemotongan atau pemungutan oleh pihak ketiga ( $\mathrm{PPh}$ pasal 21, 22, 23, dan 24).

Menurut Mardiasmo (2016), besarnya angsuran pajak dalam tahun berjalan yang harus dibayar sendiri oleh Wajib Pajak untuk setiap bulan adalah sebesar Pajak Penghasilan yang terhutang menurut Surat Pemberitahuan Pajak Tahunan Pajak Penghasilan tahun pajak yang lalu dikurangi dengan: (a) Pajak penghasilan yang dipotong sebagaimana dimaksud 
dalam Pasal 21 dan Pasal 23, serta Pajak Penghasilan yang dipungut sebagaimana dimaksd dalam Pasal 22; dan (b) Pajak Penghasilan yang dibayar atau terutang di luar negeri yang boleh dikreditkan sebagaimana dimaksud dalam Pasal 24, dibagi 12 (dua belas) atau banyak bulan dalam bagian tahun pajak. Setiap Wajib Badan yang melakukan kegiatan usaha akan dikenai Pajak Penghasilan (PPh) Pasal 25 berupa angsuran PPh setiap bulannya. Dalam arti, $\mathrm{PPh} 25$ Badan adalah pembayaran pajak yang dilakukan dengan angsuran dengan tujuan untuk meringankan beban Wajib Pajak Badan. Ada 3 klasifikasi tarif PPh 25 yang berlaku bagi badan usaha berdasarkan tingkat peredaran brutonya, yakni:

1. Jika penghasilan bruto kurang dari Rp. 4,8 milliar, maka tarif pajak adalah $1 \%$ dikalikan pengasilan kotor (peredaran bruto).

2. Jika penghasilan lebih besar dari Rp. 4,8 milliar sampai dengan Rp. 50 milliar, maka perhitungannya adalah $0,25-(0,6$ milliar/penghasilan kotor $) \mathrm{x}$ PKP

3. Jika lebih dari Rp. 50 milliar, maka perhitungannya $25 \%$ x PKP

Menurut Jusuf (2013), sebagaimana ketentuan yang ada, setiap perusahaan yang beroperasi diwajibkan membayar pajak, termasuk pajak PPh pasal 25. Menjadikan data akuntansi sebagai dasar atau informasi penentuan besaran pajak yang dikenakan dalam menjalankan kegiatannya, turut serta dalam membayar pajak PPh pasal 25 yang juga menjadikan akuntansi sebagai acuan didalam menentukan besaran pajak PPh pasal 25. Ismail et al. (2014) menyatakan bahwa CV. Delta Dharma telah menggunakan tarif perhitungan pajak penghasilan sesuai dengan Undang-Undang Pajak Penghasilan No. 36 Tahun 2008 namun dalam hal pembayaran atau penyetoran pajak CV. Delta Dharma sering mengalami keterlambatan karena belum adanya karyawan yang langsung menangani pajak pada perusahaan tersebut. Koraag (2014) menunjukan bahwa dalam penerapan akuntansi pajak penghasilan, muncul kewajiban pajak tangguhan mengakibatkan jumlah beban pajak menjadi besar dan sebaliknya jika muncul aktiva pajak tangguhan maka jumlah beban pajak penghasilan menjadi kecil. Menurut Walandouw (2013), PPh pasal 23 berpengaruh terhadap besarnya angsuran PPh Pasal 25 yang harus dibayarkan perusahaan, sedangkan PPh Pasal 25 tidak mempunyai pengaruh apapun terhadap PPh pasal 23. Pelaporan $\mathrm{PPh}$ pasal 23 paling lambat tanggal 10 bulan berikutnya dan SPT masa disampaikan paling lambat 20 hari setelah masa pajak berakhir. Sedangkan pelaporan PPh Pasal 25 paling lambat tanggal 15 bulan berikutnya dan SPT masa disampaikan paling lambat 20 hari setelah masa pajak berakhir. Menurut Sejanto et al. (2018), koreksi fiskal sangat perlu dilakukan karena dapat membantu dalam rangka perhitungan pajak penghasilan badan, sehingga pihak Wajib Pajak dapat melakukan pembayaran pajak secara benar sesuai dengan peraturan perpajakan yang berlaku. Menurut Kurniawan et al. (2017), terdapat selisih pajak penghasilan yang dihemat setelah dilakukan penghitungan dengan menggunakan perencanaan pajak pada tahun 2016. Penerapan strategi pelaksanaan pajak, perusahaan memiliki beberapa kebijakan-kebijakan akuntansi yang dijadikan acuan, selain itu perusahaan juga melakukan beberapa langkah seperti, memaksimalkan penghasilan yang dikecualikan dengan cara memaksimalkan penghasilan bunga, memaksimalkan biaya fiskal dan meminimalkan biaya yang tidak diperkenankan sebagai pengurang penghasilan.

\section{METODE PENELITIAN}

Jenis penelitian yang digunakan dalam penelitian ini adalah penelitian kualitatif dengan pendekatan deskriptif. Menurut Sugiyono (2016), metode penelitian kualitatif merupakan salah satu jenis penelitian yang spesifikasinya adalah sistematis, terencana dan tersruktur dengan jelas sejak awal hingga pembuatan desain penelitiannya. Menurut Moleong (2017), pengertian penelitian kualitatif adalah penelitian yang bermaksud untuk memahami fenomena tentang apa yang dialami subjek penelitian misalnya, perilaku, persepsi, motivasi, tindakan, dan lainnya, secara holistik, dan dengan cara deskripsi dalam bentuk kata-kata dan 
bahasa, pada suatu konteks khusus yang alamiah dan dengan memanfaatkan berbagai metode ilmiah. Sumber data yang dikemukakan dalam penelitian ini adalah data primer dan data sekunder. Teknik pengumpulan data yang seharusnya gunakan dalam penelitian ini adalah observasi, wawancara, dan dokumentasi. Menurut Sulistyo (2014), metode dan proses analisa yang digunakan dalam penelitian terdiri dari 3 yaitu metode analisis deskriptif, uji validitas, dan analisis komparatif (perbandingan), dimana analisis ini membandingkan pajak penghasilan atas jasa PT. Surya Fajar Mas dengan Undang-Undang Nomor 36 Tahun 2008.

\section{HASIL PENELITIAN DAN PEMBAHASAN}

\subsection{Hasil penelitian}

Laporan keuangan merupakan hasil akhir akuntansi yang disusun berdasarkan Standar Akuntansi Keuangan dengan periode 1 Januari sampai dengan 31 Desember. Laporan keuangan PT. Surya Fajar Mas terdiri dari neraca, laba rugi, laporan arus kas, dan catatan atas laporan keuangan. Laporan laba rugi adalah laporan yang menggambarkan hasil usaha suatu perusahaan dalam satu periode dengan unsur-unsur terkait adalah pendapatan dan beban yang merupakan dasar dalam penentuan jumlah pajak penghasilan terutang.

\subsection{Pembahasan}

Penelitian ini dilakukan untuk mengetahui perhitungan pajak penghasilan pasal 25 pada PT. Surya Fajar Mas menurut Undang-Undang yang berlaku. Berdasarkan data-data yang telah dikumpulkan maka perhitungan PPh 25 disajikan pada Tabel 1.

Tabel 1. Penghitungan PPh pasal 25 atas PT. Surya Fajar Mas

\begin{tabular}{lr}
\hline & \multicolumn{2}{r}{ Disajikan dalam Rp. } \\
\hline Penghasilan kena pajak: & $1,755,194,251$ \\
Penghasilan bruto & $936,103,601$ \\
Pengasilan neto setelah koreksi fiskal & - \\
Kerugian fiskal & $936,103,601$ \\
Penghasilan Kena Pajak & $9,361,036$ \\
PPh terutang (1\% x Rp. 936,103,601) & \\
\cline { 2 - 2 } Angsuran PPh Pasal 25 tahun berikutnya: & 780,086 \\
PPh pasal 25 (1/12 x Rp. 9,361,036)
\end{tabular}

Sumber: Data olahan, 2019

Dari hasil penghitungan maka PPh Pasal 25 dari PT. Surya Fajar Mas adalah sebesar Rp. 9,361,036 (peredaran bruto dibawah Rp. 4.8 miliar) dan di angsur sejumlah Rp. 780,086 tiap bulan pada tahun pajak berikutnya. Pada penelitian ini perhitungan pajak penghasilan menurut laporan laba rugi komersial sama dengan perhitungan menurut laba rugi fiskal yang disebabkan karena tidak adanya pendapatan dan biaya/beban yang tidak diakui dalam akuntansi perpajakan tetapi menurut akuntansi komersial diakui sebagai pendapatan pendapatan dan biaya/beban.

\section{KESIMPULAN DAN SARAN}

\subsection{Kesimpulan}

Peranan pajak sebagai penerimaan bagi negara kita, merupakan sumber utama yang masih sangat potensial untuk ditingkatkan agar penerimaan dari pajak mampu memenuhi seluruh pembiayaan bagi Negara. Undang-undang No 17 Tahun 2000 yang merupakan perubahan dari Undang-Undang No 7 Tahun 1983 tentang Pajak Penghasilan, memberikan wewenang kepada Wajib Pajak untuk menghitung, melaporkan dam membayar sendiri pajak terutang yang disebut self Assesment system, dimana fiskus melakukan tugas member 
penyuluhan, pembinaan dan pengawasan. Berdasarkan hasil pembahasan dapat disimpulkan beberapa hal yang menjadi topik pembahasan penelitian ini adalah sebagai berikut:

1. PT. Surya Fajar Mas telah melaksanakan kewajiban formal, yaitu melaksanakan pembukuan, pelaporan dan pembayaran pajak secara teratur.

2. PT. Surya Fajar Mas menggunkan metode pencatatan akrual dalam pengakuan pendapatan usaha dan beban usaha baik dalam laporan akuntansi secara komersial maupun laporan akuntansi secara fiskal.

3. PT. Surya Fajar Mas telah melaksanakan pelaporan pajak penghasilan pada SPT Tahunan sesuai dengan ketentuan.

4. PT. Surya Fajar Mas telah melakukan koreksi fiskal sesuai dengan Undang-Undang Perpajakan yang berlaku yaitu Undang-Undang Pajak Penghasilan Nomor 17 Tahun 2000.

\subsection{Saran}

Saran dari penelitian ini adalah:

1. PT. Surya Fajar Mas agar selalu memperhatikan dan melakukan komunikasi dengan pihak fiskus untuk mengetahui ketentuan-ketentuan yang paling akhir, baik berupa keputusan Menteri Keuangan maupun Surat Edaran Dirjen Pajak, serta informasi lainnya yang berhubungan dengan pajak melalui berita pajak.

2. PT. Surya Fajar Mas sebaiknya menerapkan perencanaan pajak penghasilan yaitu dengan merinci secara jelas pendapatan lain-lain dan kerugian lain-lain agar tidak menimbulkan keraguan-keraguan pihak fiskus dalam melakukan pemeriksaan pajak.

3. Seluruh transaksi beban PT. Surya Fajar Mas baik operasional maupun administrasi dan umum serta beban-beban lainnya sebaiknya didukung bukti-bukti yang kuat dan sah. Bukti-bukti tersebut lalu di administrasikan dan diarsipkan dengan baik sebagai bukti pertanggung jawaban atas pengeluaran yang dilakukan.

4. Manajemen sebaiknya merekrut karyawan khusus untuk menangani pajak agar supaya pembayaran atau penyetoran pajak sesuai dengan ketentuan dan tata cara perpajakan.

\section{DAFTAR PUSTAKA}

Ismail, S., Pangemanan, S., S., \& Sabijono, H. (2014). Analisis perhitungan, penyetoran dan pelaporan pajak penghasilan pasal 25 pada CV. Delta Dharma. Jurnal EMBA: Jurnal Riset Ekonomi Manajemen dan Bisnis Akuntansi, 2(2), 1491-1499. https://ejournal.unsrat.ac.id/index.php/emba/article/view/4870

Jusuf, V. S. (2013). Penerapan akuntansi terhadap pajak penghasilan pasal 25 pada PT. Sinar Pacifik Internusa Manado. Jurnal EMBA: Jurnal Riset Ekonomi Manajemen dan Bisnis Akuntansi, 1(3), 593-598. https://ejournal.unsrat.ac.id/index.php/emba/article/view/1865.

Koraag, E. A. (2014). Analisis dan penerapan akuntansi Pajak Penghasilan Pasal 25 UU No. 36 tahun 2008 pada PT. BPR Celebes. Jurnal EMBA: Jurnal Riset Ekonomi Manajemen dan Bisnis Akuntansi, 2(4), 471-480. https://ejournal.unsrat.ac.id/index.php/emba/article/view/6351.

Kurniawan, S., Morasa, J., \& Walandouw, S., K. (2017). Evaluasi penerapan perencanaan pajak atas pajak penghasilan (PPh Pasal 25) pada PT. Bank SulutGo. Going Concern: Jurnal Riset Akuntansi, 12(1) 220-232 https://doi.org/10.32400/gc.12.01.17208.2017.

Mardiasmo. (2016). Perpajakan. Yogyakarta: Penerbit Andi.

Moleong, L. J. (2017). Metodologi penelitian kualitatif, Edisi Revisi tahun 2017. Bandung: PT. Remaja Rosdakarya.

Soemitro, R. (1992). Pengantar singkat hukum pajak. Bandung: Eresco. 
Resmi, S. (2016). Perpajakan Teori dan Kasus, Jakarta: Salemba Empat.

Sejanto, T. W., Elim, I., \& Tirayoh, V. Z. (2018). Analisis perhitungan, pencatatan dan pelaporan pajak penghasilan pasal 25 pada CV. Venus Kumersot Raya. Going Concern: Jurnal Riset Akuntansi, 13(2), 464-475. https://doi.org/10.32400/gc.13.02.19644.2018.

Sulistyo, B. (2014). Metode Penelitian. Jakarta: Penaku.

Sugiyono. (2016). Metode Penelitian kuantitatif, Kualitatif, dan R\&D. Bandung: Alfabeta.

Waluyo. (2016). Akuntansi Pajak, Edisi 6. Jakarta: Salemba Empat.

Walandouw, P. (2013). Analisis perhitungan dan pelaporan PPh pasal 23 dan PPh pasal 25. Jurnal EMBA: Jurnal Riset Ekonomi Manajemen dan Bisnis Akuntansi, 1(3), 987997. https://ejournal.unsrat.ac.id/index.php/emba/article/view/1908/1516.

Widyaningsih. (2015). Hukum pajak dan perpajakan. Bandung: Alfabeta.

Zain, M. (2009). Manajemen perpajakan, Edisi 3. Jakarta: Salemba Empat. 